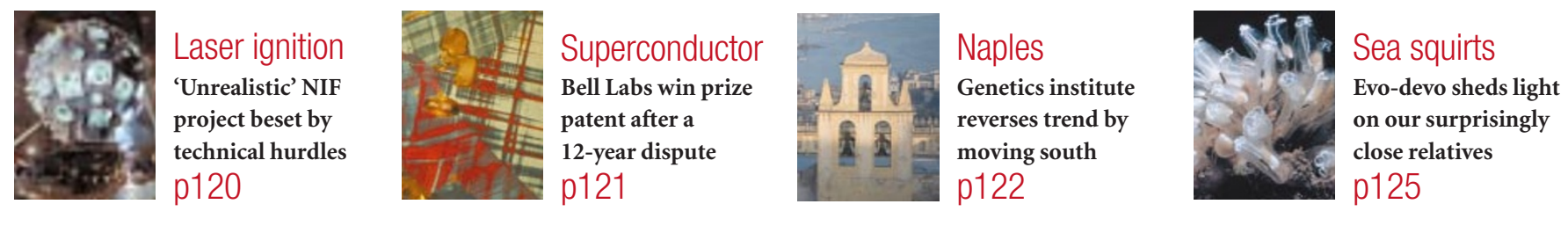

\title{
Celera turns to public genome data to speed up endgame...
}

\section{Washington and Paris}

Celera Genomics Corporation appears to have cut back on its plans to singlehandledly complete a high-quality sequence of the human genome. The company now says that it intends to achieve the same end by combining lower-quality sequence with data from the international, publicly funded Human Genome Project (HGP).

At a press conference on Monday in Rockville, Maryland, Celera announced that it had itself sequenced 81 per cent of the human genome, and had combined this with publicly available data to cover 90 per cent of the genome.

Craig Venter, the Celera president, said the company plans to stop sequencing the human genome at the ' $4 \mathrm{X}$ ' level in June meaning that four bases of sequence have been generated for every base of genome instead of $10 \mathrm{X}$, as originally planned.

Celera's formation in 1998 led to an acceleration of the public project, which is funded by the US National Institutes of Health and Department of Energy, and Britain's Wellcome Trust (see Nature 395, 207, 1998). Its use of public data means that Celera will now sequence the human genome fewer times than previously planned. "If we had to only use our own data, we might have to go as high as 10X," Venter said.

Instead, it will combine these data with the $5 \mathrm{X}$ draft that the publicly funded project is expected to produce this spring. Venter described Celera's use of the public data as a "de facto collaboration", and said the company would "give attribution and credit" to the public project.

The acknowledgement seems to mark the end of Celera's original plan to 'shotgun sequence' the whole human genome on its own by sequencing millions of DNA fragments without knowing where they belong in the genome, and then use sophisticated software to work out which fragment goes where.

Now Celera will need to hang its sequence data on the framework produced by the public project. Celera used the same approach to sequence the Drosophila genome, in collaboration with the Berkeley Genome Sequencing Project (see Nature 401, 729; 1999).

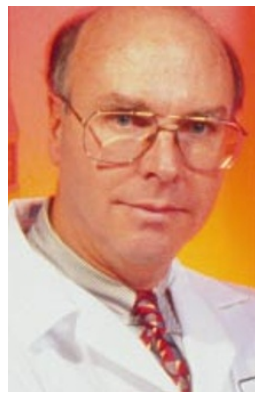

Venter: modifying sequencing plans.
Celera claimed at its press conference to have sequenced 81 per cent of the human genome, but only to a depth of 1.75X. Combining these data with the public sequence has raised the total to 90 per cent, at $2 X$ coverage.

Hamilton Smith, 1978 Nobel laureate in medicine and a cofounder of Celera, who is now its senior director of DNA resources, said the company's shotgun data match up well with the HGP's 'clone-by-clone' data. "Eighty per cent of the public sequence is covered in our data."

The public data represent about 50 per cent of the total in Celera's database, so the 20 per cent of unique data provided by the HGP represents a net 10 per cent contribution beyond Celera's, Smith explained.

John Sulston, director of Britain's Sanger Centre in Cambridge, where one third of the public sequencing is being carried out, points out that Celera's coverage is only to a depth of $1.5 \mathrm{X}$, whereas the public project has already completed half of the sequence at $5 \mathrm{X}$.

He says the Celera press release could be rewritten to say that, with the company's 1.5 $\mathrm{X}$ data on top of the $5 \mathrm{X}$ data, "half [the genome] is really very well covered", and that Venter has helped "extend our 50 per cent".

Members of the public effort have agreed to deposit their sequence data every 24 hours. Because Celera hasn't accepted any public money, it is under no obligation to make its data public, but Venter repeated on Monday that it will eventually do so.

Venter estimated that the combined data contain 2.58 billion base pairs (Gb), and that 97 per cent of human genes are now in the company's database. But he declined to estimate the number of genes these data contain, adding that most genes are still in fragments.

Philip Green, a biocomputing expert at the University of Washington, estimates that the sequencing output of Celera and the public project are running neck and neck, at $1.5 \mathrm{~Gb}$ per month. He says the total amount of raw data required for adequate coverage of the genome could be obtained by the summer, provided the data from both groups are combined. "Neither group seems likely to get to that point by itself before the end of the year," he says. Paul Smaglik and Declan Butler

\section{... as Internet fervour hits genomics}

\section{London}

When the dust settles over the recent dramatic upsurge in the value of biotechnology stocks - with the price of shares in some companies increasing threeor fourfold within a few weeks - a key role in triggering the goldrush could be credited to a US investment website visited regularly by many thousands of small investors.

The most dramatic news has come from Celera Genomics of Rockville, Maryland (see above). The company's announcement on Monday that it has compiled sequence data from its own and publicly funded efforts covering 90 per cent of the human genome sent its stock soaring, at one point reaching a value of $\$ 258$, compared with $\$ 186$ the previous Friday.

Shares in other genomics and biotechnology companies received a parallel boost from the news, with the Nasdaq Biotech Index rising by 7.6 per cent. The value of shares in companies with a direct involvement in genomics has skyrocketed in recent weeks (see Nature 403, 4; 1999).

Stock analysts point to several recent announcements to help explain this surge of interest, including the public sequencing of the one-billionth human nucleotide pair (see Nature 402,$331 ; 1999)$ and the publication of the complete sequence of chromosome 22 (see Nature 402, 447; 1999).

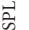


Equally significant appears to have been an announcement nine days before Christmas by the managers of a website known irreverently as The Motley Fool (TMF) that they had decided to purchase $\$ 50,000$ of shares in Celera Genomics to add to their portfolio of 'rule breaker' companies.

The impact of the announcement, coming from a group of investors who had been among the first to spot key Internet stocks such as America OnLine - whose shares, purchased in 1994 at 46 cents, are now worth more than $\$ 70$ - was electric. While the number of shares purchased in Celera had previously been running at about 150,000 a day, this was multiplied overnight by a factor of more than ten.

The explosion in demand was rapidly reflected in the price of Celera stock. Having hovered around $\$ 40$ for much of the autumn, it had been growing steadily to reach a value of $\$ 72$ by 16 December, the day of the TMF announcement.

Within three trading days the value of the shares had shot up to $\$ 125$, and this momentum was maintained in the days to come. The shares reached a high for the year of $\$ 193$ on 30 December; the previous

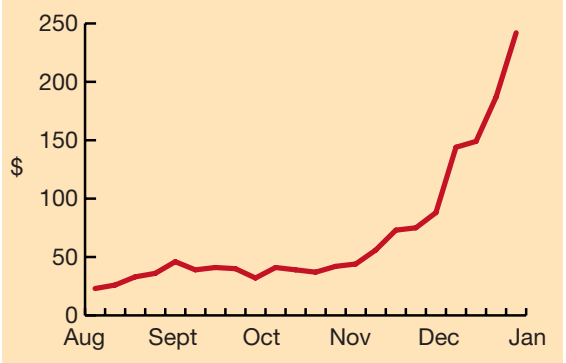

On the up and up: Celera's share price has taken off dramatically in recent weeks.

August, they had been down to $\$ 22$.

After dropping slightly as a result of profit-taking in the days immediately after the Christmas break, the shares took off again, defying predictions that the preChristmas increase in value would be shortlived. Last Friday, trading in Celera stock was halted when the company announced plans for its Monday press conference.

Analysts say that many of those who have been buying up genomics stocks at such speed seem to be individuals who have already profited from the recent growth in the value of Internet stocks, and have been attracted to genomics because of the similarities between the two fields.

"People have been saying that

biotechnology is like the Internet, but until recently the stock has been much cheaper," says Genghis Lloyd-Davies of Credit Suisse First Boston.

Managers at TMF reflect this new-found enthusiasm. The decision to invest heavily in Celera was taken after assessing the extent to which the company fitted the strict criteria they have laid down for the selection of 'rule breaker' stock.

One of these, as described in a statement explaining the investment last month, was the fact that Celera appeared to be the dominant company in a rapidly growing area of commercial significance. "Celera has more 'momentum' - more speed - than any other company that we've ever bought," said the statement.

TMF managers acknowledge that their decision to invest in Celera reflects a longterm commitment. Dave Gardner, one of the founders of the website says: "We believe that in this coming century more value will be created in biotechnology than in any other technology."

David Dickson

\section{Inadequate optics 'threat to US laser facility'}

Washington

A series of technical obstacles could block completion of the US National Ignition Facility (NIF), according to an interim project review delivered this week to Bill Richardson, the Secretary of Energy.

The huge laser facility is under construction at the Lawrence Livermore National Laboratory in California. But major optical components may be unable to carry the NIF lasers at the intensity originally envisaged, says the review, by a task force of the Secretary of Energy's Advisory Board.

Optical damage will occur in these fused silica lenses at a lower intensity of laser light than was expected when the NIF was designed, because they will be operating in a vacuum - a conclusion that the authors admit is "a surprise".

They also say it will be hard to keep the equipment clean, because of "very cramped assembly areas" in the NIF building. And they warn that it will be difficult to order and procure 30,000 small optics components to adequate specification.

But the task force, chaired by John McTague, former technical director of the Ford Motor Company, concludes that the NIF can still be completed, although it will take longer and cost more than planned. "The task force has not uncovered any technical obstacle that would clearly prevent completion and operation of the NIF sys- tem," said McTague, releasing the interim report on Monday (10 January).

The task force recommends that Livermore should assemble 96 lasers - half the original total - and use each of them at half their originally designed power to prevent damage to the fused silica optics. It then suggests a pause in the project before assembling the other lasers and raising the power intensity to the original design level by 2007 four years later than originally planned.

Asked if overruns on the $\$ 1.2$ billion project would be much more than $\$ 300$ million - widely floated since problems emerged on the project last September - McTague said, "I don't know". He agrees that construction of the NIF began with "unrealistic" expectations, "because there wasn't enough fleshing out of the 'hows' of the project".

The task force criticizes Vic Reis, assistant secretary of energy responsible for defence programmes when NIF was started, for allowing it to proceed with contingency funding of only 15 per cent. This "may be appropriate for the construction of an apartment building, [but it] is too low for this challenging and unique project," says the review, adding that such projects should have a contingency of 30 or 35 per cent.

It also says that the "scientific culture" of the Lawrence Livermore laboratory hindered the execution of such a large engineering project, and criticizes its director, Bruce
Tarter, for failing to take direct responsibility for the NIF - even now. "The project needs to report directly to him," McTague says. "He needs to insert himself into the process." Tarter was unavailable for comment.

The task force found, however, that problems with cleanliness during laser assembly inside the NIF building could be solved by importing outside expertise. These problems were initially cited by laboratory officials as the main reason for the project's problems (see Nature 401, 101; 1999), although the McTague review spells out far broader technical and management difficulties running across the entire project.

A spokesman for the Department of Energy said that it would respond to the review when the final report was deliveredit is expected in the spring. Critics of the NIF say the review's technical content shows that the project won't work. "What makes sense is to halt the project, build one beam and see if it works," says Chris Paine of the Natural Resources Defense Council, an anti-nuclear group that opposes the project.

But Burt Richter, former director of the Stanford Linear Accelerator Center and a member of the task force, rejects charges from environmentalists that the review had been too kind. "This is a hard-hitting report," Richter says. "It says that a laser intensity of half the design is a shoo-in, but anything else is quite risky.” Colin Macilwain 